\title{
Investigation into microstructure and element segregation of Inconel 713LC during SLM processing using modified cellular automaton model
}

\author{
Amir Ansari Dezfoli \\ National Cheng Kung University \\ Yu-Lung Lo ( $\square$ loyl@mail.ncku.edu.tw ) \\ National Cheng Kung University \\ M. Mohsin Raza \\ National Cheng Kung University
}

\section{Research Article}

Keywords: IN713LC SLM, SLM, element segregation

Posted Date: January 4th, 2021

DOI: https://doi.org/10.21203/rs.3.rs-135441/v1

License: (c) (1) This work is licensed under a Creative Commons Attribution 4.0 International License.

Read Full License 


\title{
Investigation into microstructure and element segregation of Inconel
}

\section{LC during SLM processing using modified cellular automaton}

\author{
model \\ Amir Reza Ansari Dezfoli ${ }^{1}$; Yu-Lung Lo ${ }^{1, *}$; M. Mohsin Raza ${ }^{1}$ \\ ${ }^{1}$ Department of Mechanical Engineering, National Cheng Kung University,No.1, Daxue Rd., East Dist., \\ Tainan City 701, Taiwan. \\ *corresponding. loyl@mail.ncku.edu.tw
}

\begin{abstract}
A numerical and experimental investigation is performed into the feasibility of fabricating IN713LC components using selective laser melting (SLM) through an appropriate control of the solidification speed, microstructure formation and element segregation. A modified Cellular Automaton (CA) model is developed to explore the nucleation, grain growth and element segregation behavior of IN713LC during ultrafast solidification. It is found that the undesired phase formation which occurs during SLM processing of IN713LC is caused by the micro segregation of $\mathrm{Nb}, \mathrm{Ti}, \mathrm{Mo}$ and $\mathrm{C}$ at the grain boundaries. It is further shown that the micro segregation intensity depends on the solidification speed, which is determined in turn by the laser energy density. In particular, a lower laser energy density increases the solidification speed and results in a more uniform solid phase, thereby reducing the risk of crack formation. The simulation results are verified by experimental investigation. The results confirm that a lower laser energy density reduces the crack density and crack length. Finally, a crackfree IN713LC SLM sample is successfully produced by reducing the energy density from 360 to $170 \mathrm{~J} / \mathrm{m}$.
\end{abstract}

\section{Introduction}

IN713LC, a nickel alloy with a composition of Cr-Al-Mo-Ti-Nb-Zr, is known for its good fatigue resistance, excellent mechanical properties, superior oxidation resistance and enhanced resistance to degradation under harsh operating condition ${ }^{1-3}$ Many studies have shown that Ni-based superalloys, such as IN71 $8^{4,5}$ IN625 and Hastelloy X $\mathrm{X}^{7}$ can be successfully fabricated by selective laser melting (SLM). However, due to its crackprone nature, the SLM processing of IN713LC is extremely challenging. Previous studies have reported the formation of three main phases in IN713LC components built by SLM, namely $\gamma, \gamma$ and carbide ${ }^{8,9}$ Among these phases, $\gamma$ phase is the main phase and has the same composition as the nominal IN713LC alloy, while $\gamma$ and carbides are secondary phases and have compositions of $\mathrm{Ni} 3 \mathrm{Nb}$ and $\mathrm{MC}$, respective ${ }^{10}$ where $\mathrm{M}$ is the metal element and $\mathrm{C}$ is carbon.

Besides the usual factors affecting the processability of SLM, such as the thermal stress, raw powder material quality and pre-printing procedure, IN713LC is also prone to crack 
formation as the result of a significant segregation and depletion of the strengthening elements from the $\gamma$ phase during solidification ${ }^{1,11-13}$ The formation of a large mushy zone further prompts crack formation through the suppression of liquid metal feeding in solidification zone $\mathrm{e}^{14}$

Due to the extremely rapid rate of solidification during SLM, experimental investigations provide only limited insights into the microstructure formation and element segregation behavior during cooling. Thus, in exploring the mechanisms which render the SLM processing of IN713LC so challenging, simulation models are widely preferred. Cellular Automaton (CA) is recognized as one of the best simulation methods for examining ultra-fast solidification processes such as SLM. Ao et al ${ }^{15}$ used CA to simulate the microstructure of AlSi10Mg during SLM based on an analysis of the thermodynamic-driven growth kinetics of the solid-liquid interface and melt pool composition. Trivedi ${ }^{16}$ examined the grain growth rate using the Kurz-GiovanolaTrivedi model. Their simulation demonstrated that the cooling rate during SLM process was around $10^{5}-10^{6} \mathrm{~K} / \mathrm{s}$. It was additionally shown that during the solidification process, the equiaxed grain formation increased with an increasing pre-heating temperature or reducing scanning speed. Zinoviev et a ${ }^{17}$ developed a two-dimensional CA model to evaluate the grain structure of metallic alloys during SLM processing. The results showed that the $\mathrm{CA}$ model yielded accurate predictions of the main characteristics of the alloy microstructure following SLM. Lain et al ${ }^{18}$ examined the microstructure evolution of IN718 during additive manufacturing using a threedimensional CA model and showed that the CA model can simulate the different microstructure forms of IN718 such as columnar grins, fine and course equiaxed grains using a complex 3D transition thermal model.

However, the literature presently lacks any simulation studies on the grain structure evolution and element segregation of IN713LC during SLM processing. Accordingly, the current study develops a modified CA model to predict the microstructure and micro segregation behavior of IN713LC during rapid solidification. The model takes account of boundary and bulk nucleation and grain growth and equations of solute diffusion have been also coupled with CA model. A particular effort has been made to develop a practical and accurate model for elements partition coefficient during SLM processing under conditions far from equilibrium conditions. The simulation results are used to determine the SLM conditions which enable the crack-free printing of IN713LC components. The validity of the derived conditions is demonstrated by means of experimental trials.

\section{Results}

The microstructures and element compositions of the IN713LC samples fabricated using energy densities of 360, 280 and $210 \mathrm{~J} / \mathrm{m}$ (corresponding to cooling rates of $4.3 \times 10^{4}, 5.5 \times 10^{4}$ and $7.3 \times 10^{4} \mathrm{~K} / \mathrm{s}$, respectively) were simulated using the CA model. The simulations were conducted in $2 \mathrm{D}$ boxes with widths and heights of $200 \mu \mathrm{m} \times 90$ $\mu \mathrm{m}, 175 \mu \mathrm{m} \times 80 \mu \mathrm{m}$ and $150 \mu \mathrm{m} \times 70 \mu \mathrm{m}$, corresponding to energy densities of 360 , 280 and $210 \mathrm{~J} / \mathrm{m}$, respectively. (Note that the box dimensions were set in accordance with the melt pool size observed in experimental single laser track SLM trials performed under the same energy density conditions.)

The composition of the initial IN713LC powder is shown in Table 1. In implementing the CA model, the IN713LC alloy was considered to be a 6-element system consisting of Cr-Mo-Nb-Al-Ti-C (i.e., the matrix component $\mathrm{Ni}$ was deliberately excluded). Note 
that the $\mathrm{C}$ component of the alloy was retained in the model even though its concentration is extremely low (0.05 wt.\%, see Table 1) due its importance in prompting hot cracking 9 . Furthermore, equal diffusion was assumed for all of the components in both the solid phase and the liquid phase, and no-flux boundary conditions were applied at all the boundaries. Table 2 summarizes the parameters applied in the micro-segregation model for the different elements of the IN713LC alloy. It is noted that $\mathrm{C}_{0}$ denotes the initial element concentration in the powder, and $\mathrm{k}$ is the equilibrium partition coefficient obtained in the low-speed continuous casting of IN713LC. The physical parameters employed in the CA model are listed in Table 3.

Table 1 Chemical composition of IN713 LC (mass \%)

\begin{tabular}{ccccccc}
\hline $\mathrm{Ni}$ & $\mathrm{Cr}$ & $\mathrm{Mo}$ & $\mathrm{Nb}$ & $\mathrm{Al}$ & $\mathrm{Ti}$ & $\mathrm{C}$ \\
\hline Bal. & 12.1 & 4.1 & 2.0 & 6.2 & 0.77 & 0.05 \\
\hline
\end{tabular}

Table 2 Parameters used in micro-segregation model for different alloying elements of IN713LC.

\begin{tabular}{ccccccc} 
Parameter & $\mathrm{Cr}$ & $\mathrm{Mo}$ & $\mathrm{Nb}$ & $\mathrm{Al}$ & $\mathrm{Ti}$ & $\mathrm{C}$ \\
\hline $\mathrm{C}_{0} \times \%[\mathrm{mass}]$ & 12.1 & 4.10 & 2.0 & 6.2 & 0.77 & 0.05 \\
$\mathrm{D} \times 10^{10}\left[\mathrm{~m}^{2} / \mathrm{s}\right]^{19}$ & 8.98 & 10.76 & 10.53 & 11.10 & 10.99 & 43.0 \\
13 & 0.96 & 0.82 & 0.46 & 0.83 & 0.55 & 0.12 \\
\hline
\end{tabular}

Table 3 Physical parameters used in CA model.

\begin{tabular}{cc}
\hline Parameter & Value \\
\hline CA Cell size $[\mu \mathrm{m}]$ & 0.2 \\
$n_{s, \max }\left[1 / \mathrm{m}^{3}\right]^{19}$ & $1.5 \times 10^{6}$ \\
$n_{v, \max }\left[1 / \mathrm{m}^{3}\right]^{19}$ & $1.5 \times 10^{7}$ \\
$T_{L}[K]^{14}$ & 1622 \\
$T_{S}[K]^{14}$ & 1523 \\
$\Delta T_{s, \max }[\mathrm{K}]^{20}$ & 3.5 \\
$\Delta T_{s, \sigma}[\mathrm{K}]^{20}$ & 0.2 \\
$\alpha\left[\mathrm{m}^{2} / \mathrm{s}\right]^{21}$ & $4.7 \times 10^{-6}$ \\
$k_{T}[\mathrm{~J}(\mathrm{~s} \mathrm{~m} \mathrm{~K})-1]^{21}$ & 18.3 \\
$\Gamma[\mathrm{K} / \mathrm{m}]^{22}$ & $3.15 \times 10^{-7}$ \\
$\Delta \mathrm{H}[\mathrm{kJ} / \mathrm{kg}]^{21}$ & 236 \\
$c_{p}[\mathrm{~J} /(\mathrm{g} \cdot \mathrm{K})]^{21}$ & 0.668 \\
\hline
\end{tabular}

Table 4 lists the results obtained of the CA model for the non-equilibrium partition coefficients of $\mathrm{Cr}, \mathrm{Mo}, \mathrm{Nb}, \mathrm{Al}, \mathrm{Ti}$ and $\mathrm{C}$ during solidification given different values of the laser energy density. It is seen that the different elements have different solubilities in the IN713LC matrix. In particular, the $\mathrm{C}, \mathrm{Nb}, \mathrm{Ti}, \mathrm{Al}$ and Mo elements have relatively low solubilities in the solid matrix, and hence tend to segregate in liquid. By contrast, $\mathrm{Cr}$ has a higher solubility, and thus tends to be trapped in the solid. It is noted that $\mathrm{C}$ has the highest diffusion coefficient of all the components in IN713LC and therefore moves through the solid-liquid interface easier than the other elements. The rapid diffusion of $\mathrm{C}$ atoms can be attributed to their small size, which allows them to sit interstitially within the Ni-super alloy lattice and hence move faster by jumping from one interstice to another. 
Comparing the equilibrium partition coefficients in Table 2 with the non-equilibrium element partition coefficients in Table 4, it is seen that their values tend toward unity as the cooling rate increases, i.e., the energy density reduces. In other words, a more uniform element concentration is obtained under lower energy densities. This finding is reasonable since, as the energy density decreases, the solidification speed increases, and hence the elements have less time to diffuse from the solid phase to the liquid phase. In other words, the high-speed solid-liquid interface traps the elements in the solid phase before they can pass through the solid-liquid interface and reach the liquid phase. It is hence inferred that different segregated components will be formed under higher solidification speeds.

Table 4. Average IN713LC element partition coefficients under different solidification rates.

\begin{tabular}{ccccccc}
$\begin{array}{c}\text { Energy Density } \\
{[\mathrm{J} / \mathrm{m}]}\end{array}$ & $\mathrm{Cr}$ & $\mathrm{Mo}$ & $\mathrm{Nb}$ & $\mathrm{Al}$ & $\mathrm{Ti}$ & $\mathrm{C}$ \\
\hline 360 & 0.97 & 0.87 & 0.60 & 0.84 & 0.71 & 0.15 \\
280 & 0.98 & 0.89 & 0.63 & 0.85 & 0.73 & 0.17 \\
210 & 0.98 & 0.90 & 0.71 & 0.86 & 0.76 & 0.21
\end{tabular}

Figures 1 3 show the simulation results for the grain structure and $\mathrm{Nb}, \mathrm{Ti}$ and $\mathrm{C}$ concentrations at different solidification percentages (i.e., 10\%, 50\% and 100\%) and energy densities of 360, 280 and $210 \mathrm{~J} / \mathrm{m}$, respectively. (Note that $\mathrm{Nb}$, Ti and $\mathrm{C}$ are deliberately selected here since they have the lowest partition coefficients among all the elements in IN713LC, as shown in Table 4.) In general, the results reveal that a lower energy density leads to a more dominant columnar grain growth structure along the solidification direction. In addition, a higher energy density results in a greater number of equiaxed grains above the columnar grains (see Fig. 1, for example, for the maximum energy density of $360 \mathrm{~J} / \mathrm{m}$ ). The greater volume fraction of equiaxed grains can be attributed to the lower temperature gradient produced at higher energy densities (i.e., $4.5 \times 10^{5} \mathrm{~K} / \mathrm{m}$ at an energy density of $360 \mathrm{~J} / \mathrm{m}$, compared to $5.8 \times 10^{5}$ and $7.8 \times 10^{5}$ $\mathrm{K} / \mathrm{m}$ at energy densities of $280 \mathrm{~J} / \mathrm{m}$ and $210 \mathrm{~J} / \mathrm{m}$, respectively). More specifically, a lower temperature gradient results in the formation of equiaxed grains in front of the columnar grains, whereas a higher temperature gradient promotes directional growth.

The element concentration distribution results shown in Figs. 1 3 show that the surface and grain boundaries are enriched in $\mathrm{Nb}, \mathrm{Ti}$ and $\mathrm{C}$. A high element concentration at the surface is reasonable since the surface is the last remaining liquid region during the solidification process, and is enriched with segregated elements from the lower stream of the melt pool. Once this region solidifies, the elements have no other liquid phase to be rejected to and are hence confined to the solid phase at the surface. The element distribution results in Fig. 1 show an obvious segregation of the $\mathrm{Nb}, \mathrm{Ti}$ and $\mathrm{C}$ elements at the grain boundaries, even under a 50\% solidification state. However, no such microsegregation effect is observed under lower energy densities of $280 \mathrm{~J} / \mathrm{m}$ and $210 \mathrm{~J} / \mathrm{m}$, respectively. Hence, it can be inferred that SLM processes performed under higher energy densities (i.e., slower solidification speeds) will produce more intensive micro segregation of the elements. In other words, the likelihood of carbide or secondary phase formation at the grain boundaries is increased specially with the present of $\mathrm{Nb}$ and $\mathrm{Ti}$. $\mathrm{Nb}$ is founded as a strong carbide former ${ }^{9}$. In addition, based on the previous research, Ti is also known to control the formation of carbide during the solidification 23. Then, segregation of both $\mathrm{Nb}$ and Ti during the solidification is important and even small difference may result in different conditions. 

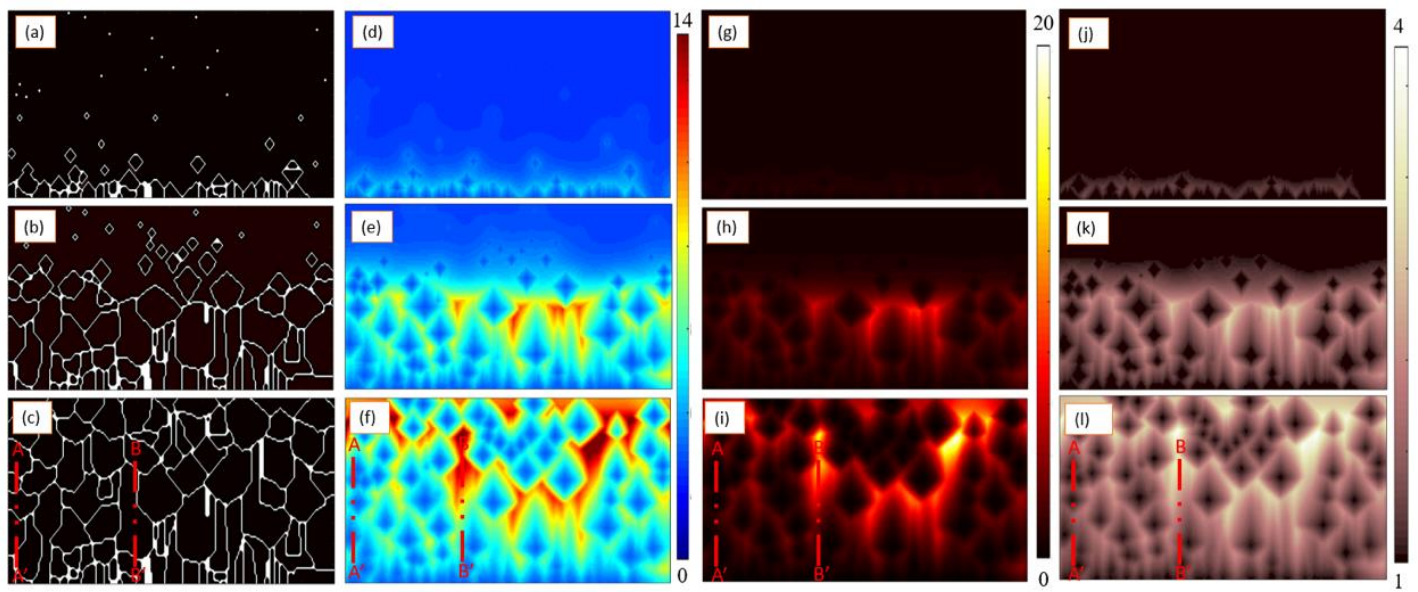

Figure 1. Simulation results for solidification behavior at energy density of $360 \mathrm{~J} / \mathrm{m}$. (a) grain structure after $10 \%$ solidification, (b) grain structure after $50 \%$ solidification, (c) grain structure after full solidification. (d) $\mathrm{Nb}$ concentration after $10 \%$ solidification, (e) $\mathrm{Nb}$ concentration after $50 \%$ solidification, (f) $\mathrm{Nb}$ concentration after full solidification. (g) Ti concentration after $10 \%$ solidification, (h) $\mathrm{Ti}$ concentration after $50 \%$ solidification, (i) $\mathrm{Ti}$ concentration after full solidification. (j) $\mathrm{C}$ concentration after $10 \%$ solidification, (k) C concentration after $50 \%$ solidification, (l) $\mathrm{C}$ concentration after full solidification.
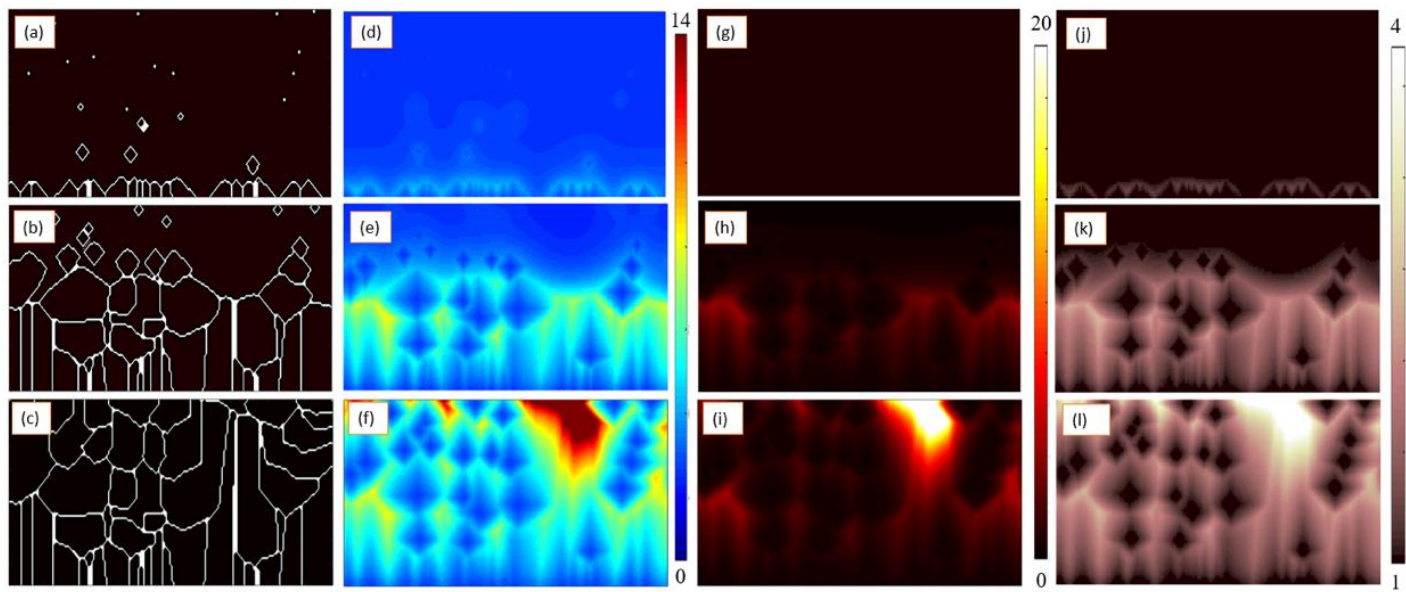

Figure 2. Simulation results for solidification behavior at $280 \mathbf{J} / \mathbf{m}$. (a) grain structure after $10 \%$ solidification, (b) grain structure after $50 \%$ solidification, (c) grain structure after full solidification. (d) $\mathrm{Nb}$ concentration after $10 \%$ solidification, (e) $\mathrm{Nb}$ concentration after $50 \%$ solidification, (f) $\mathrm{Nb}$ concentration after full solidification. (g) Ti concentration after $10 \%$ solidification, (h) Ti concentration after $50 \%$ solidification, (i) $\mathrm{Ti}$ concentration after full solidification. (j) $\mathrm{C}$ concentration after $10 \%$ solidification, (k) $\mathrm{C}$ concentration after $50 \%$ solidification, (l) $\mathrm{C}$ concentration after full solidification. 

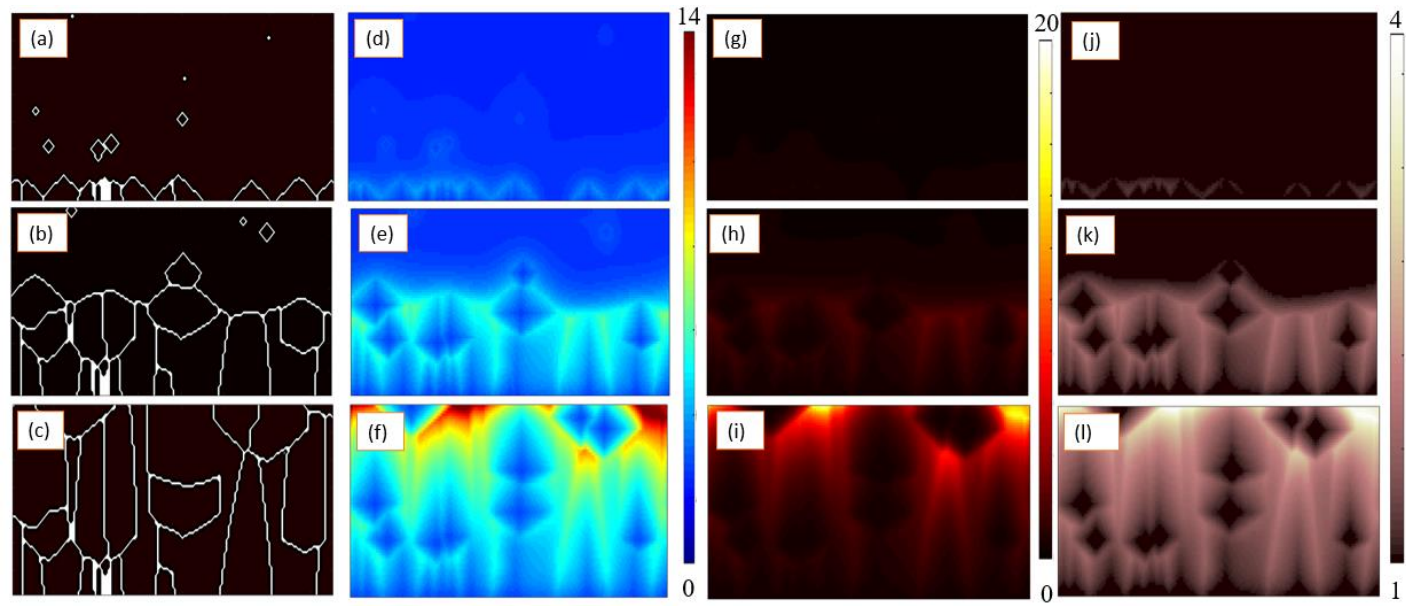

Figure 3. Simulation results for solidification behavior at $210 \mathbf{J} / \mathbf{m}$. (a) grain structure after $10 \%$ solidification, (b) grain structure after $50 \%$ solidification, (c) grain structure after full solidification. (d) $\mathrm{Nb}$ concentration after $10 \%$ solidification, (e) $\mathrm{Nb}$ concentration after $50 \%$ solidification, (f) $\mathrm{Nb}$ concentration after full solidification. (g) Ti concentration after 10\% solidification, (h) Ti concentration after 50\% solidification, (i) Ti concentration after full solidification. (j) C concentration after 10\% solidification, (k) C concentration after $50 \%$ solidification, (l) $\mathrm{C}$ concentration after full solidification.

A detailed inspection of the simulation results presented in Figs. 1 3 shows that not all the grain boundaries exhibit the same amount of segregation. For example, when large and elongated grains encounter other grains during the growth process, a grain boundary with a high element concentration is formed. In general, grains with a larger size inevitably accrue a greater amount of segregation in front of their solid-liquid interface. When the segregated liquid is confined by other grains in the upstream region of the melt pool (particularly in the dense area of equiaxed grains), the segregated elements are confined at the interface between them, and hence a region of high element concentration is formed. Notably, however, the equiaxed grains may sometimes decrease the formation of segregated elements if, for example, they are formed directly in front of a columnar grain when the segregated level ahead of the solid-liquid interface of columnar grain still is not too high. The regions indicated by lines AA' and BB' in Figs. 1(c, f, j and l) are typical cases in point. For example, AA' shows a uniform and dense equiaxed grain located immediately above the melt pool boundary. The presence of this grain physically suppresses element segregation at the boundary of the advancing grain. By contrast, line BB' shows the presence of an equiaxed grain in front of a large grain with a high level of segregation at the solid front. In this condition, a high segregated area is formed within the system. Base on the role of equiaxed grains on segregation, many researchers ${ }^{23,24}$ have attempted to suppress element segregation at the grain boundary in additive manufacturing processes by lowering the temperature gradient in order to increase the number of equiaxed grains. However, pre-heating requires the use of a middle frequency inductive power to provide heat to the substrate and a thermometer to perform temperature monitoring. Consequently, the present study deliberately adopts a simpler strategy for controlling the grain boundary segregation effect in the SLM processing of IN713LC by controlling the solidification speed through an appropriate setting of the laser power and scanning speed, respectively.

Figure 4 presents optical microscope $(\mathrm{OM})$ images of the ground and polished IN713LC samples printed using energy densities of 360, 280 and $210 \mathrm{~J} / \mathrm{m}$, respectively. It is seen that all of the samples contain cracks of various lengths. For each sample, the cracks are randomly dispersed and are orientated mainly parallel to the solidification 
direction. The OM images also show the presence of sub-micrometric spherical pores formed as the result of gas entrapment ${ }^{24}$. As predicted by the simulation results, the crack density and crack length decrease with a reducing energy density. In particular, the crack density and average crack length reduce from $0.103 \%$ and $79 \mu \mathrm{m}$ for an energy density of $360 \mathrm{~J} / \mathrm{m}$ to $0.029 \%$ and $62 \mu \mathrm{m}$ for an energy density of $210 \mathrm{~J} / \mathrm{m}$, as shown in Table 5. According to the simulation results, the lower degree of cracking at a lower energy density can be attributed to the faster cooling rate, which suppresses element segregation at the grain boundaries and generates a more uniform element distribution. As a result, the formation of undesired phase, which leads to crack initiation, is reduced.
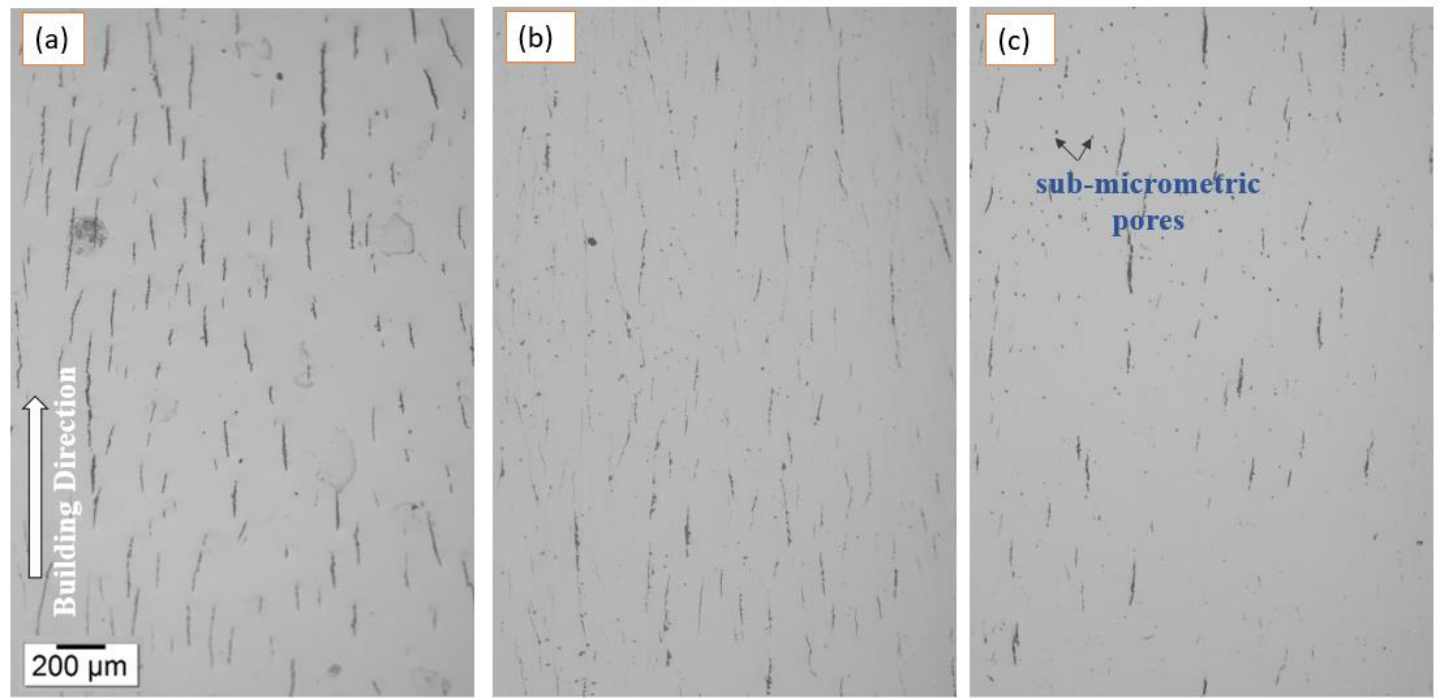

Figure 4. OM images of ground and polished IN713LC samples built using different energy densities: (a) $360 \mathrm{~J} / \mathrm{m}$; (b) $280 \mathrm{~J} / \mathrm{m}$; (c) $210 \mathrm{~J} / \mathrm{m}$.

Table 5. Crack density and average crack length for different energy densities.

\begin{tabular}{ccc}
$\begin{array}{c}\text { Energy density } \\
{[\mathrm{J} / \mathrm{m}]}\end{array}$ & $\begin{array}{c}\text { Crack density } \\
{[\%]}\end{array}$ & $\begin{array}{c}\text { Average crack length } \\
{[\mu \mathrm{m}]}\end{array}$ \\
\hline 360 & 0.103 & 79 \\
\hline 280 & 0.082 & 69 \\
\hline 210 & 0.029 & 62
\end{tabular}

Figure 5 presents a high-magnification SEM image and corresponding EBSD results for the crack region of the IN713LC sample built using an energy density of $210 \mathrm{~J} / \mathrm{m}$. A dominant cracking pattern is clearly observed along the grain boundary region. The cracks extend along the grain boundaries, or are located at the point of intersection of neighboring grains. Overall, the straight shape of the cracks, and their location at the grain boundaries, indicates that they are formed as the result of segregation-induced grain boundary liquation0. Notably, the experimental results are consistent with the simulation predictions that the majority of the cracks are located at the grain boundaries. 


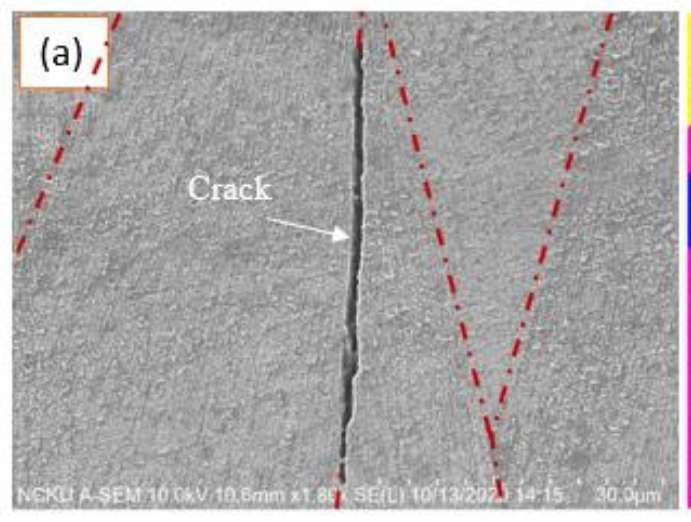

Figure 5. Crack details: (a) backscattered SEM micrograph; (b) EBS
in as-fabricated IN713LC sample.

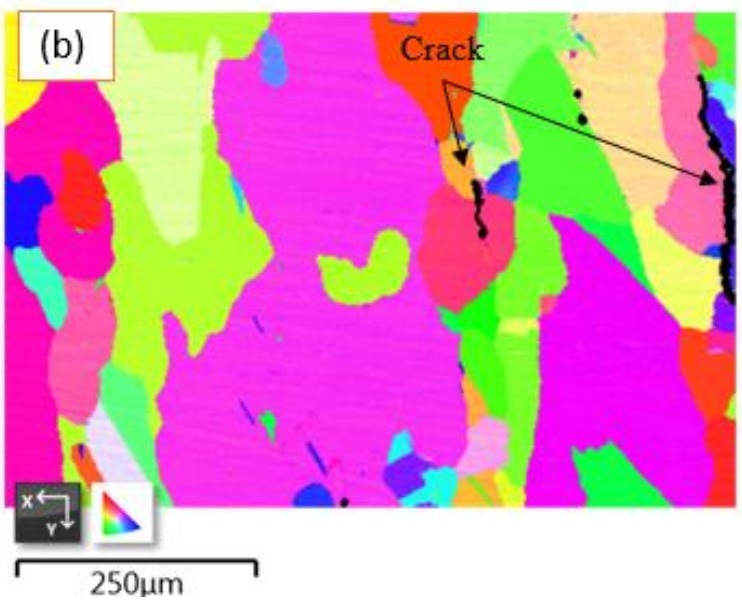

To verify the role of element segregation in prompting crack formation in the present samples, a detailed EDS analysis was performed at selected points inside and outside of the cracks formed in the sample built with a high energy density of $360 \mathrm{~J} / \mathrm{m}$. The analysis points and corresponding EDS results are presented in Fig. 6. As predicted by the simulation results, both crack regions exhibit a high segregation rate of $\mathrm{Nb}, \mathrm{Ti}, \mathrm{Al}$ and $\mathrm{C}$. In particular, the $\mathrm{Ti}, \mathrm{Nb}, \mathrm{Al}$ and $\mathrm{C}$ contents increase from 0.77, 2.0, 6.2 and 0.05 wt.\% in the original IN713LC powder to 24.42, 11.54, 16.08 and 21.54 wt.\%, respectively, within the crack. The high concentration of metallic elements implies the formation of MC carbides within the crack, and is hence consistent with the simulation results for the non-equilibrium element partition coefficients listed in Table 4.

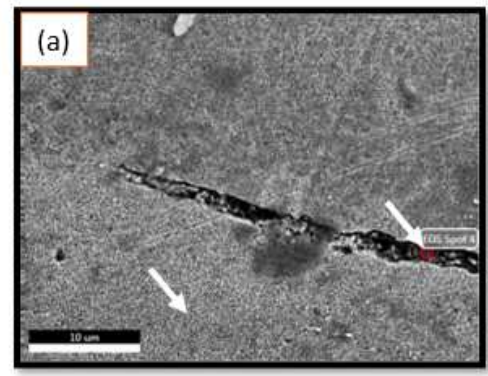

\begin{tabular}{|c|c|c|c|c|c|c|}
\hline (b) & $\mathrm{Cr}$ & $\mathrm{Mo}$ & $\mathrm{Nb}$ & $\mathrm{Al}$ & $\mathrm{Ti}$ & $\mathrm{C}$ \\
\hline $\begin{array}{c}\text { Initial } \\
\text { Powder }\end{array}$ & 12.1 & 4.1 & 2.0 & 6.2 & 0.77 & 0.05 \\
\hline $\begin{array}{c}\text { Inside of } \\
\text { crack }\end{array}$ & 4.43 & 2.65 & 11.54 & 16.08 & 24.42 & 21.54 \\
\hline $\begin{array}{c}\text { Outside of } \\
\text { crack }\end{array}$ & 22.24 & 4.08 & 0.78 & 4.23 & 0.64 & 2.82 \\
\hline
\end{tabular}

Figure 6. Element concentration in IN713LC sample fabricated using energy density of $360 \mathrm{~J} / \mathrm{m}$. (a) Points selected for EDS analysis, (b) alloying element concentrations inside and outside of crack.

In general, the simulation and experimental results presented above indicate that a lower energy density (i.e., a faster solidification rate) is beneficial in suppressing crack formation in SLM IN713LC components. Accordingly, a further sample was printed using a laser power of $150 \mathrm{~W}$ and a scanning speed of $850 \mathrm{~mm} / \mathrm{s}$; corresponding to a reduced energy density of around $170 \mathrm{~J} / \mathrm{m}$. To eliminate the sub-micrometric spherical pores formed at low energy densities, the scan spacing was reduced to compensate for the shrinkage of the melt pool. Figure 7 presents an OM image of the built sample. It is seen that the surface contains neither cracks nor visible pores. In other words, the feasibility of SLM for the processing of IN713LC is confirmed given a suitable low value of the laser energy density. It is noted, however, that reducing the energy density below a certain critical value may potentially induce new defects such as 'void formation' due to melt pool shrinkage under low energy conditions ${ }^{14}$. Accordingly, 
determining the optimal value of the energy density is an essential requirement for future studies.

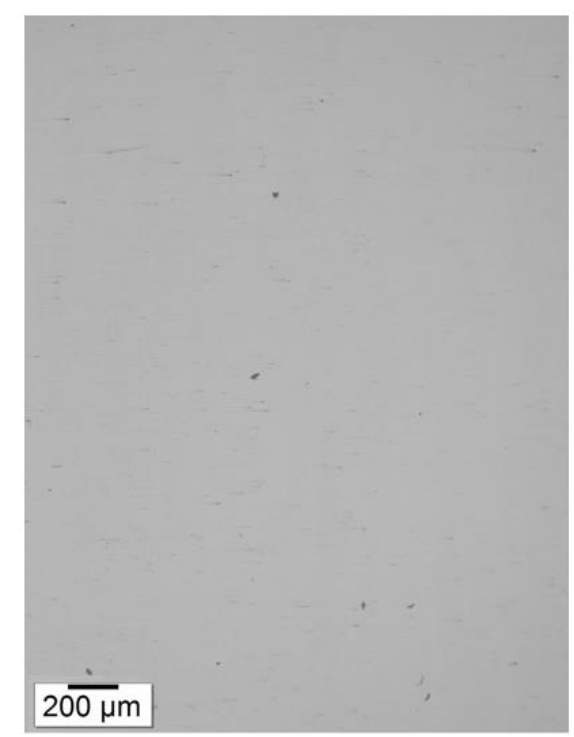

Figure 7. IN713LC sample fabricated using low energy density of $170 \mathrm{~J} / \mathrm{m}$.

\section{Discussion}

A modified CA model has been developed to predict the microstructure and micro segregation behavior of IN713LC nickel alloy during the solidification stage of the SLM process. The model takes explicit account of the grain nucleation and growth mechanisms and solute diffusion of the alloying elements, respectively. The simulation results show that the micro segregation phenomenon is a diffusion-controlled process, in which the elements with a lower partition coefficient and higher diffusivity experience a higher rate of segregation. It is additionally shown that element segregation is enhanced under a slower solidification rate since the elements spend a longer time in their respective precipitation windows and thus have sufficient time to move from the solid phase to the liquid phase. The simulation results also indicate that, among all the alloying elements of IN713LC, the Nb, Ti, C elements exhibit the highest rate of micro segregation during solidification. Finally, as the laser energy density reduces, the solidification speed increases and the element partitioning coefficients approach unity. Consequently, a more uniform solid phase is formed with only minimal segregation at the grain boundaries. The simulation results have been verified by means of experimental trials. It has been shown that the crack length and crack density decrease with a reducing laser energy density. The experimental results are thus consistent with the simulation predictions for the effects of the laser energy density on the element segregation effect at the grain boundary during solidification. Notably, the experimental results have demonstrated for the first time the feasibility of fabricating crack-free IN713LC components using the SLM process given a suitable low value of the energy density (e.g., $170 \mathrm{~J} / \mathrm{m}$ in the present case). 


\section{Methods}

This section describes the modified CA model developed in the present study to examine the microstructural evolution of IN713LC during SLM processing and the corresponding element segregation behavior. The section commences by introducing the models used to describe the nucleation and growth of the IN713LC microstructure as a function of the undercooling temperature. The section then describes the approach taken to model the element segregation behavior based on the principles of solute diffusion. Finally, the section outlines the CA simulation procedure used to predict the grain structure and micro-segregation effect in IN713LC during the rapid solidification stage of the SLM process.

\section{Nucleation and grain growth models}

The number of nucleation sites formed during liquid phase solidification is conventionally assumed to have a Gaussian distribution as a function of the undercooling temperature and can be modelled using the following equation ${ }^{25}$ :

$$
\frac{d n}{d(\Delta T)}=\frac{n_{\max }}{\sqrt{2 \pi}} \exp \left[-\frac{\left(\Delta T-\Delta T_{\max }^{0}\right)^{2}}{2 \Delta T_{\sigma}^{2}}\right],
$$

where $\Delta T$ is the undercooling temperature, $\Delta T_{\max }^{0}$ is the maximum nucleation undercooling temperature, $\Delta T_{\sigma}$ is the standard deviation of the undercooling temperature, and $n_{\max }$ is the maximum nucleation density. The total density of the nucleation sites can thus be modeled as

$$
n(\Delta T)=\int_{0}^{\Delta T} \frac{d n}{d(\Delta T)} d(\Delta T) .
$$

Since the IN713LC alloy system is dominated by Ni ( 75wt.\%, see Table 1$)$, the undercooling temperature, $\Delta T$, can be assumed to consist of only thermodynamic undercooling $\Delta T_{T}$. That is,

$$
\Delta T=\Delta T_{T}
$$

The thermodynamic undercooling, $\Delta T_{T}$, can be expressed $\mathrm{as}^{25}$ :

$$
\Delta T_{T}=\frac{\Delta H}{c_{p}} I v\left(P_{t}\right)
$$

where $c_{p}, \Delta H, P_{t}$ and $I v$ are the specific heat, latent heat, Peclet number and Ivantsov function, respectively. The Ivantsov function has the form ${ }^{25}$

$$
I v\left(P_{t}\right)=P_{t} \exp \left(P_{t}\right) \int_{P_{t}}^{\infty} \frac{e^{-\eta}}{\eta} d \eta .
$$

In addition, the Peclet number is defined as ${ }^{25}$

$$
P_{t}=\frac{v_{\text {growth }} R}{2 \alpha}
$$

where $v_{\text {growth }}$ is the liquid / solid growth speed, $\alpha$ is the thermal diffusivity, and $R$ is the dendrite tip radius. According to Trivedi ${ }^{26}$ and Kurz and Fisher ${ }^{27}$, the growth speed and dendrite tip radius are related via the following stability criterion:

$$
\mathrm{R}=\frac{c_{p} \Gamma}{0.025 P_{t} \Delta H}
$$

where $\Gamma$ is the Gibbs-Thomson coefficient. From Eqs. (6) and (7), the growth rate can be obtained as

$$
v_{\text {growth }}\left[\frac{m m}{s}\right]=1.5 \Delta T^{2}-2.1 \Delta T
$$




\section{Element segregation}

In modeling the element segregation behavior during solidification, the governing equation for solute diffusion is given as ${ }^{15}$

$$
\frac{\partial C_{i}}{\partial t}=\nabla \cdot D_{i}(T) \nabla C_{i}+\left(C_{L, i}^{*}-C_{s, i}^{*}\right) \frac{\partial f_{S}}{\partial t},
$$

where $D_{i}$ is the solute diffusion coefficient of component $i(\mathrm{Cr}, \mathrm{Mo}, \mathrm{Nb}, \mathrm{Al}$, Ti and $\mathrm{C}$ in the present case). In addition, the third term in Eq. (9) is the solute source term which is segregated at the solid-liquid interface and $C_{L, i}^{*}$ and $C_{S, i}^{*}$ are the solute concentrations of component $i$ at the solid-liquid interface, respectively. Under equilibrium conditions, the two solute concentration terms at the solid-liquid interface are related as follows:

$$
C_{s, i}^{*}=k_{i} C_{L, i}^{*}
$$

where $k_{i}$ is the equilibrium partition coefficient of element $i$. However, for the rapid solidification rate considered in the present study, the non-equilibrium relation between the element concentrations in the liquid and solid phases is given as

$$
C_{S, i}^{*}=\frac{k_{i}+{ }^{a_{0} R_{S}} / D_{i}}{1+{ }^{a_{0} R_{S}} / D_{i}} C_{L, i}^{*}
$$

where $a_{0}$ is the length of atomic dimensions of the components and $R_{s}$ is the solidification rate, as computed by the CA model. From Eq. (11), when the solidification speed is slow, $R_{s} \rightarrow 0$ and $C_{s, i}^{*}=k_{i} C_{L, i}^{*}$. However, when the solidification speed is very fast, $R_{s} \rightarrow \infty$ and $C_{s, i}^{*}=C_{L, i}^{*}$. In other words, no element segregation occurs since the elements are captured by the solid phase before they can diffuse to the liquid phase.

\section{Algorithm of CA model}

The simulation domain is divided into cells with a uniform size of $0.2 \mu \mathrm{m} \times 0.2$ $\mu \mathrm{m}$. Moreover, the temperature at each point in the domain is considered to be both time- and position-dependent and is calculated as ${ }^{18,28}$ :

$$
T(z, t)=T_{L}-\dot{T} t+G_{z} Z,
$$

where $\dot{T}$ is the cooling rate and $G_{z}$ is the temperature gradient. The cooling rate can be estimated as

$$
\dot{T} \approx \frac{2 \pi k_{T}}{e}\left(T-T_{0}\right)
$$

where $k_{T}$ is the thermal conductivity of IN713LC, $e$ is the energy density, and $T_{0}$ is the reference temperature. In addition, the temperature gradient can be calculated as the following space deviation:

$$
G_{z}=\frac{\dot{T} z}{2 \alpha}
$$

It is noted that $\dot{T}$ and $G_{z}$ both depend on the energy density. In the CA model, each cell is characterized by two variables, namely the state (i.e., solid or liquid) and the crystallography orientation. In initializing the model, the system is considered to be at the liquidous temperature, and hence all of the cell states are set as 0 . However, as the temperature of each cell falls below the liquidus temperature, the cell state is changed from 0 to 1; indicating that the cell resides in the solid state. Notably, the cell state may change from 0 or 1 under the following two conditions:

- Nucleation occurs in the cell 
- The cell is captured by a solid cell.

The density of new nuclei formed during the solidification process is calculated by Eq. (1) for simulation domain at boundaries or inside the melt. The nucleation densities are then multiplied by the total numbers of cells with a state of 1 in order to determine the number of new nucleation sites. That is,

$$
\begin{array}{r}
N_{s}=\frac{n_{s \max }}{\sqrt{2 \pi}} \exp \left[-\frac{\left(\Delta T-\Delta T_{s \max }^{0}\right)^{2}}{2 \Delta T_{s \sigma}^{2}}\right] N_{a s}, \\
N_{v}=\frac{n_{v \max }}{\sqrt{2 \pi}} \exp \left[-\frac{\left(\Delta T-\Delta T_{v \max }^{0}\right)^{2}}{2 \Delta T_{v \sigma}^{2}}\right] N_{a v},
\end{array}
$$

where $N_{a s}$ is the total number of cells with state 1 at the system boundary, and $N_{a v}$ is the total number of cells with state 1 inside the bulk liquid. Furthermore, $\Delta T_{v \max }^{0}$ is considered to be $5{ }^{\circ} \mathrm{C}$ lower than $\Delta T_{\text {smax }}^{0}$. In performing the simulations, a random number, $r_{i}$, with a value between 0 and 1 is assigned to each CA cell and nucleation is assumed to occur if the following condition is then satisfied:

$$
r_{i}<\frac{N_{s}}{N_{a s}}
$$

Following nucleation, a second random process is used to generate and assign a crystallography orientation number, $q=[0-64]$, to the corresponding cell. Note that a large number of possible crystallography orientations is deliberately considered here in order to avoid impinging grains with the same orientation during the solidification process. In addition, the growth length of cell $i$ with regard to its neighbor $j$ at time $t$ is calculated as

$$
L_{i}^{j}(t)=\int_{0}^{t} v_{\text {growth }} d t
$$

Liquid neighbor capturing is also regarded as a random process. In particular, neighbor $j$ is captured by cell $i$ if the following condition is satisfied:

$$
r_{i}<\frac{L_{i}^{j}(t)}{\Delta x\left[\cos \theta_{i}+\left|\sin \theta_{i}\right|\right]}
$$

where $\Delta x$ is the cell length and $\theta$ is the crystallographic orientation, which is calculated from the state of cell $i$ as follows:

$$
\theta_{i}=\frac{\pi}{180}\left(45-90 \frac{q_{i}}{q}\right)
$$

Equations 18 and 19 show that the grain growth speed is a function of the grain orientation. In particular, the grain orientation affects the capturing rate and then drives the grain growth phenomena. After cell $i$ captures cell $j$, the orientation of cell $j$ is assigned to that of cell $i$. The solid fraction of cells, $f_{S}$, is then calculated at each time step using the following equation:

$$
f_{S}(t)=\frac{L_{i}^{j}(t)}{\Delta x}
$$

Considering the need for convergence and numerical stability, the time step in the CA simulation process is limited as follows:

$$
d t \leq \frac{1}{5}\left(\frac{\Delta x}{d f_{S}(t) / d t}, \frac{\Delta x^{2}}{D_{L}}\right) .
$$




\section{Materials and Methods}

\section{Laser processing}

The IN713LC powder used in the present study had a spherical shape with a diameter of $15-60 \mu \mathrm{m}$. The printing trials were performed on a Tongtai AM-250 SLM machine equipped with a Nd-YAG laser with a wavelength of $1064 \mathrm{~nm}$, a focal beam diameter of $100 \mu \mathrm{m}$, and a Gaussian irradiation profile. The laser provided a maximum power of $500 \mathrm{~W}$ and a maximum scanning speed of $2000 \mathrm{~mm} / \mathrm{s}$. The trials used a zig-zag scanning model with a $67^{\circ}$ rotation of the scanning direction between consecutive layers. To avoid oxidation during the SLM process, the experiments were performed in a nitrogen atmosphere with an oxygen content of less than $1000 \mathrm{ppm}$. Based on a series of preliminary experiments, the scanning process was performed using three different laser energy densities of 360, 280 and $210 \mathrm{~J} / \mathrm{m}$, respectively. For each energy density, three cubic specimens were printed with dimensions of $10 \times 10 \times 10 \mathrm{~mm}^{3}$.

\section{Characterization}

Following the SLM process, the samples were cut from the base plate with a wire and mounted on epoxy resin. The mounted samples were ground progressively with $\mathrm{SiC}$ sandpaper from a grit size of P240 to a final grit size of P3000, and were then further polished with a diamond suspension to a final particle size of around $0.3 \mu \mathrm{m}$. The polished samples were cleaned in ethanol solution and then dried. The microstructures and element compositions of the samples were examined using a scanning electron microscope (SEM, ZEISS Supra 55) equipped with energy dispersive X-ray spectroscopy (EDS) and electron backscattered diffraction (EBSD). In addition, the crack density was calculated using ImageJ software.

\section{References}

[1] Cantó, J. S., Winwood, S., Rhodes, K., \& Birosca, S., A study of low cycle fatigue life and its correlation with microstructural parameters in IN713C nickel based superalloy, Materials Science and Engineering: A, 718, 19-32, (2018).

[2] Kunz, L., Lukáš, P., Konečná, R., \& Fintová, S., Casting defects and high temperature fatigue life of IN 713LC superalloy, nternational journal of fatigue, 41, 47-51, (2012).

[3] Matysiak, H., Zagorska, M., Balkowiec, A., Adamczyk-Cieslak, B., Cygan, R., Cwajna, J., and Kurzydłowski, K. J., The microstructure degradation of the IN $713 \mathrm{C}$ nickel-based superalloy after the stress rupture tests, Journal of Materials Engineering and Performance, 23(9), 3305-3313, (2014).

[4] Wang, Z., Guan, K., Gao, M., Li, X., Chen, X. \& Zeng, X., The microstructure and mechanical properties of deposited-IN718 by selective laser melting, Journal of Alloys and Compounds,513, 513, 518-523, (2012).

[5] Choi, J.P., Shin, G.H., Yang, S., Yang, D.Y., Lee, J.S., Brochu, M. \& Yu, J.H., Densification and microstructural investigation of Inconel 718 parts fabricated by selective laser melting, Powder Technology, 310, 60-66, (2017). 
[6] Li, S., Wei, Q., Shi, Y., Zhu, Z., \& Zhang, D., Microstructure Characteristics of Inconel 625 Superalloy Manufactured by Selective Laser Melting, Journal of Materials Science \& Technology, 31(9), 946-952, (2015).

[7] Tian, Y., Tomus, D., Rometsch, P. \& Wu, X., Influences of processing parameters on surface roughness of Hastelloy $X$ produced by selective laser melting, Additive Manufacturing, 103-112, (2017).

[8] Wang, H., Zhang, X., Wang, G. B., Shen, J., Zhang, G. Q., Li, Y. P., \& Yan, M., Selective laser melting of the hard-to-weld IN738LC superalloy, Journal of Alloys and Compounds, 807, p. 151662, (2019).

[9] Chamanfar, A., Jahazi, M., Bonakdar, A., Morin, E., \& Firoozrai, A., Cracking in Fusion Zone and Heat Affected Zone of Electron Beam Welded Inconel-713LC Gas Turbine Blades, Materials Science \& Engineering A, 462, 230-240, (2015).

[10] Harrison, N. J., Selective laser melting of nickel superalloys: solidification, microstructure and material response, Doctoral dissertation, University of Sheffield, (2016).

[11] Yeh, A. C., Lu, K. W., Kuo, C. M., Bor, H. Y., \& Wei, C. N., Effect of serrated grain boundaries on the creep property of Inconel 718 superalloy, Materials Science and Engineering: A, 530, p. 525-529, (2011).

[12] Li, Z., Xiong, J., Xu, Q., Li, J. \& Liu, B., Deformation and recrystallization of single crystal nickel-based superalloys during investment casting, Journal of Materials Processing Technology, 217, 1-12, (2015).

[13] Zupanič, F., Bončina, T., Križman, A. \& Tichelaar, F.D., Structure of continuously cast Ni-based superalloy Inconel 713C, Journal of Alloys and Compounds, 329, 290-297, (2001).

[14] Wang, H. Y., Lo, Y. L., Tran, H. C., Le, T. N., \& Mohsin, M. R., Systematic Approach for Reducing Micro-Crack Formation in Inconel 713LC Components Fabricated by Laser Powder Bed Fusion, Journal of Rapid Prototype, Submitted, (2020).

[15] Ao, X., Xia, H., Liu, J. \& He, Q., Simulations of microstructure coupling with moving molten pool by selective laser melting using a cellular automaton, Materials \& Design, 185, p. 108230, (2020).

[16] Zinoviev, A., Zinovieva, O., Ploshikhin, V., Romanova, V., \& Balokhonov, R., Evolution of grain structure during laser additive manufacturing. Simulation by a cellular automata method, Materials \& Design, 106, 321-329, (2016).

[17] Lian, Y., Gan, Z., Yu, C., Kats, D., Liu, W.K. \& Wagner, G.J, A cellular automaton finite volume method for microstructure evolution, Materials and Design, 169, 107672107685, (2019). 
[18] Kundin, J., Mushongera, L. \& Emmerich, H., Phase-field modeling of microstructure formation during rapid solidification in Inconel 718 superalloy, Acta Materialia, 95, 343-356, (2015).

[19] Roucka, J., Kosour, V., Kovác, M., Krutis, V., Hrbacek, K., Plzen, M.E., \& Bites, P.V., Prediction of Solidification and Microstructure of Inconel Alloy Using Numerical Simulation, Materials Science and Engineering, 33, p. 012085, (2012).

[20] Attard, B., Cruchley, S., Beetz, C., Megahed, M., Chiu, Y.L. \& Attallah, M.M., Microstructural Control during Laser Powder Fusion to Create Graded, Additive Manufacturing, 36, p. 101432, (2020).

[21] Bonakdar, A., Molavi-Zarandi, M., Chamanfar, A., Jahazi, M., Firoozrai, A., \& Morin, E., Finite element modeling of the electron beam welding of Inconel-713LC gas turbine blades, Journal of Manufacturing Processes, 26, 339-354, (2017).

[22] Haines, M., et al., A sensitivity analysis of the columnar-to-equiaxed transition for $\mathrm{Ni}$ based superalloys in electron beam additive manufacturing, Computational Materials Science, 155, 340-349, (2018).

[23] Xu, J., Lin, X., Guo, P., Hu, Y., Wen, X., Xue, L., Liu, J., \& Huang, W., The effect of preheating on microstructure and mechanical properties of laser solid forming IN738LC alloy, Materials Science \& Engineering A, 691, 71-80, (2017).

[24] Marchese, G., et al., Study of the Microstructure and Cracking Mechanisms of Hastelloy X Produced by Laser Powder Bed Fusion, Materials, 11, p. 106, (2018).

[25] Dezfoli, A. R. A., Hwang, W. S., Huang, W. C., \& Tsai, T. W., Determination and controlling of grain structure of metals after laser incidence: Theoretical approach, Scientific reports, 7, p. 41527, (2017).

[26] Trivedi, R., Morphological stability of a solid particle growing from a binary alloy melt, Journal of Crystal Growth, 48, p. 93-99, (1980).

[27] Kurz, W. and Fisher, D., Dendrite growth at the limit of stability: tip radius and spacing, Acta Metallurgica, 29, p. 11-20, (1981).

[28] Poorhaydari, K., Patchett, B.M. \& Ivey, D.G, Estimation of cooling rate in the welding of plates with intermediate thickness, Welding journal, 84(10), 149-155, (2005).

\section{Acknowledgements}

The authors gratefully acknowledge the financial support provided to this study by the Ministry of Science and Technology of Taiwan under Grant No. MOST 108-2218-E-006-026. The research was also supported in part by the funding provided by the Ministry of Education, Taiwan, Headquarters of University Advancement, to the Intelligent Manufacturing Research Center (iMRC) at National Cheng Kung University (NCKU).

\section{Author contributions statement}

Amir Reza Ansari Dezfoli has written the microstructure code. M. Nohsin Raza did experimental measurements. Yu-Lung Lo provided insight for the result discussion and edited the manuscript. 


\section{Competing financial interests}

The authors declare no competing financial interests. 


\section{Figures}
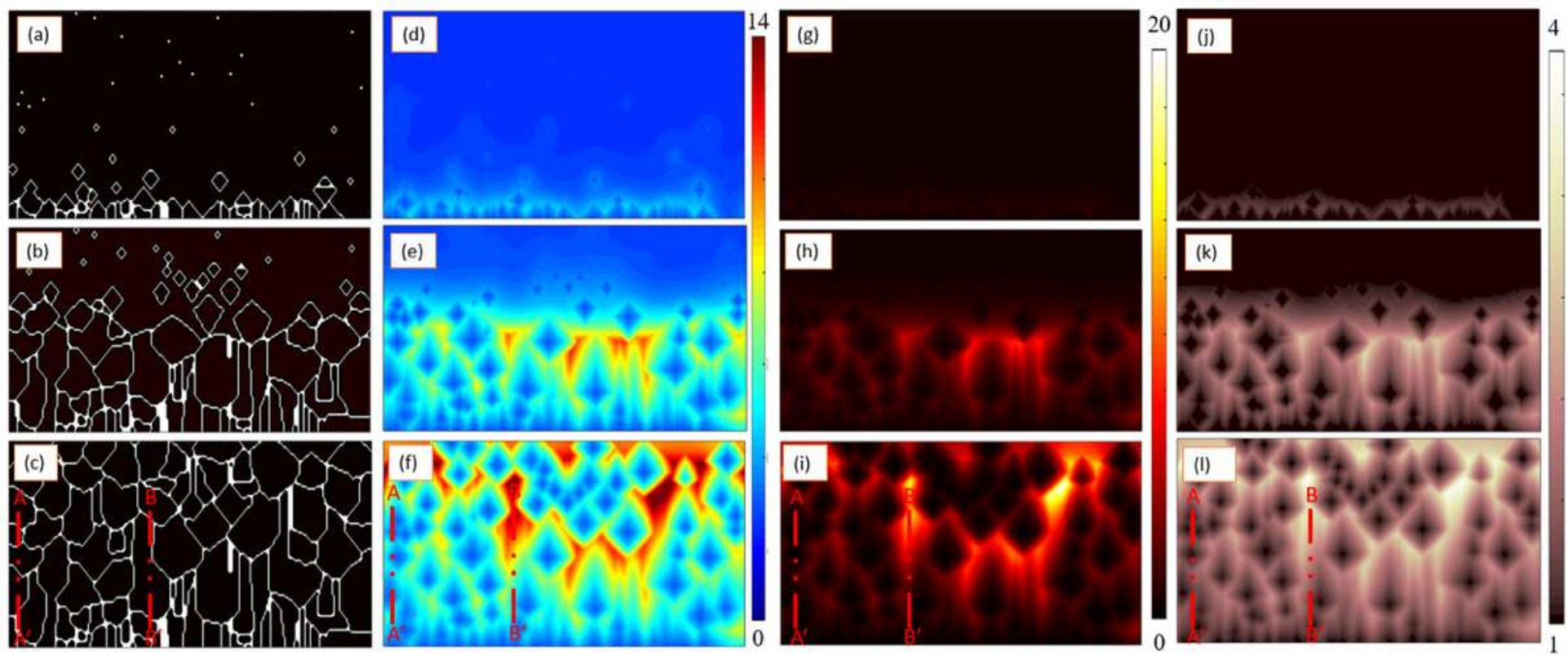

Figure 1

Simulation results for solidification behavior at energy density of $360 \mathrm{~J} / \mathrm{m}$. (a) grain structure after $10 \%$ solidification, (b) grain structure after $50 \%$ solidification, (c) grain structure after full solidification. (d) $\mathrm{Nb}$ concentration after $10 \%$ solidification, (e) Nb concentration after $50 \%$ solidification, (f) Nb concentration after full solidification. (g) Ti concentration after $10 \%$ solidification, (h) Ti concentration after $50 \%$ solidification, (i) Ti concentration after full solidification. (j) C concentration after $10 \%$ solidification, (k) C concentration after $50 \%$ solidification, (I) C concentration after full solidification.
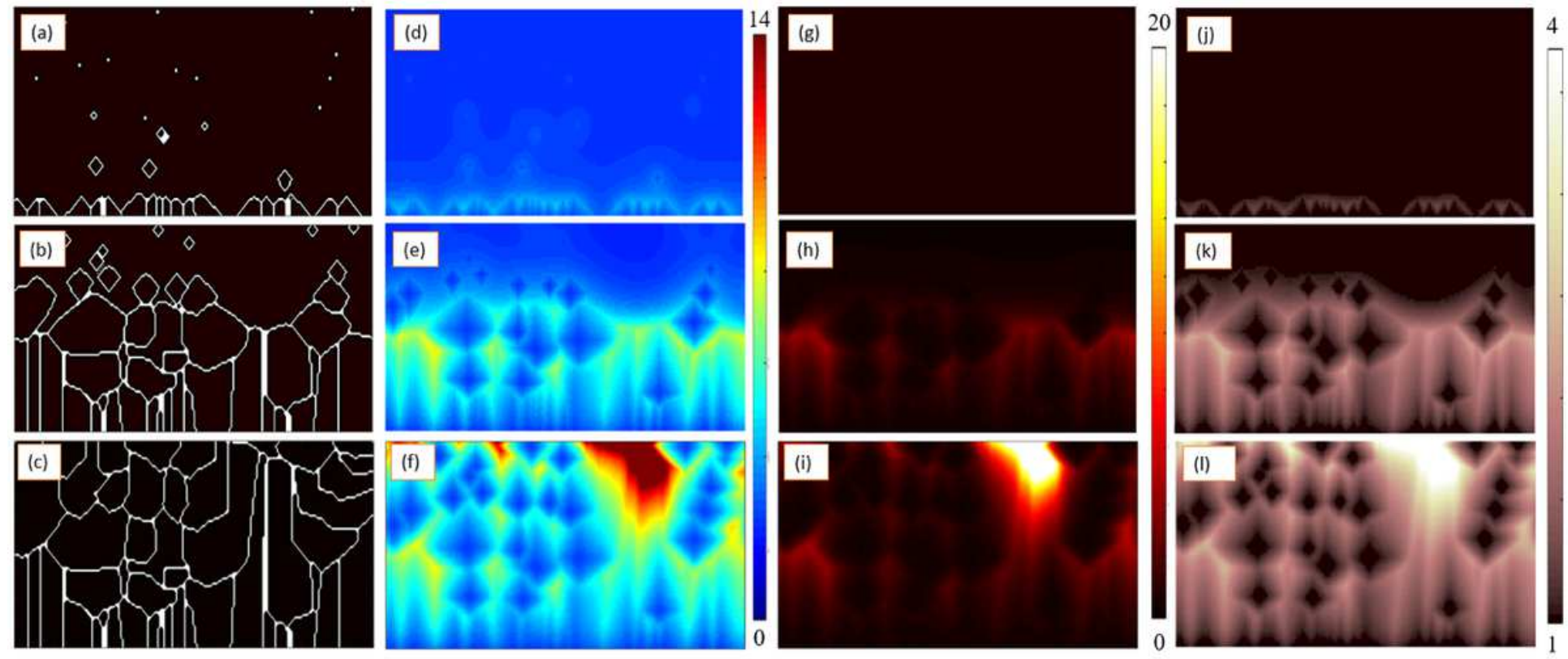

Figure 2 
Simulation results for solidification behavior at $280 \mathrm{~J} / \mathrm{m}$. (a) grain structure after $10 \%$ solidification, (b) grain structure after $50 \%$ solidification, (c) grain structure after full solidification. (d) Nb concentration after $10 \%$ solidification, (e) $\mathrm{Nb}$ concentration after $50 \%$ solidification, (f) $\mathrm{Nb}$ concentration after full solidification. (g) Ti concentration after $10 \%$ solidification, (h) Ti concentration after $50 \%$ solidification, (i) $\mathrm{Ti}$ concentration after full solidification. (j) $\mathrm{C}$ concentration after $10 \%$ solidification, $(\mathrm{k}) \mathrm{C}$ concentration after $50 \%$ solidification, (I) C concentration after full solidification.
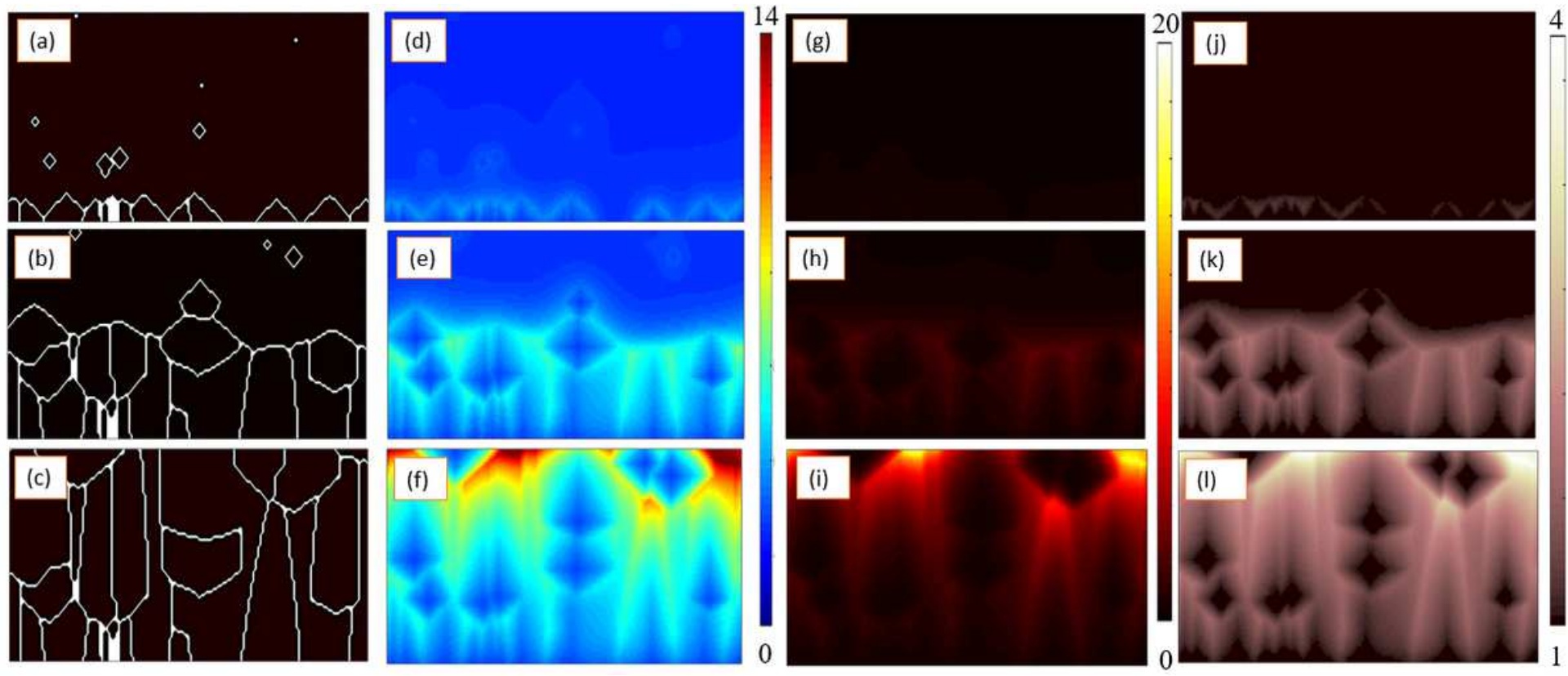

\section{Figure 3}

Simulation results for solidification behavior at $210 \mathrm{~J} / \mathrm{m}$. (a) grain structure after $10 \%$ solidification, (b) grain structure after $50 \%$ solidification, (c) grain structure after full solidification. (d) Nb concentration after $10 \%$ solidification, (e) $\mathrm{Nb}$ concentration after $50 \%$ solidification, (f) $\mathrm{Nb}$ concentration after full solidification. (g) Ti concentration after $10 \%$ solidification, (h) Ti concentration after $50 \%$ solidification, (i) Ti concentration after full solidification. (j) $\mathrm{C}$ concentration after $10 \%$ solidification, (k) C concentration after $50 \%$ solidification, (I) C concentration after full solidification. 

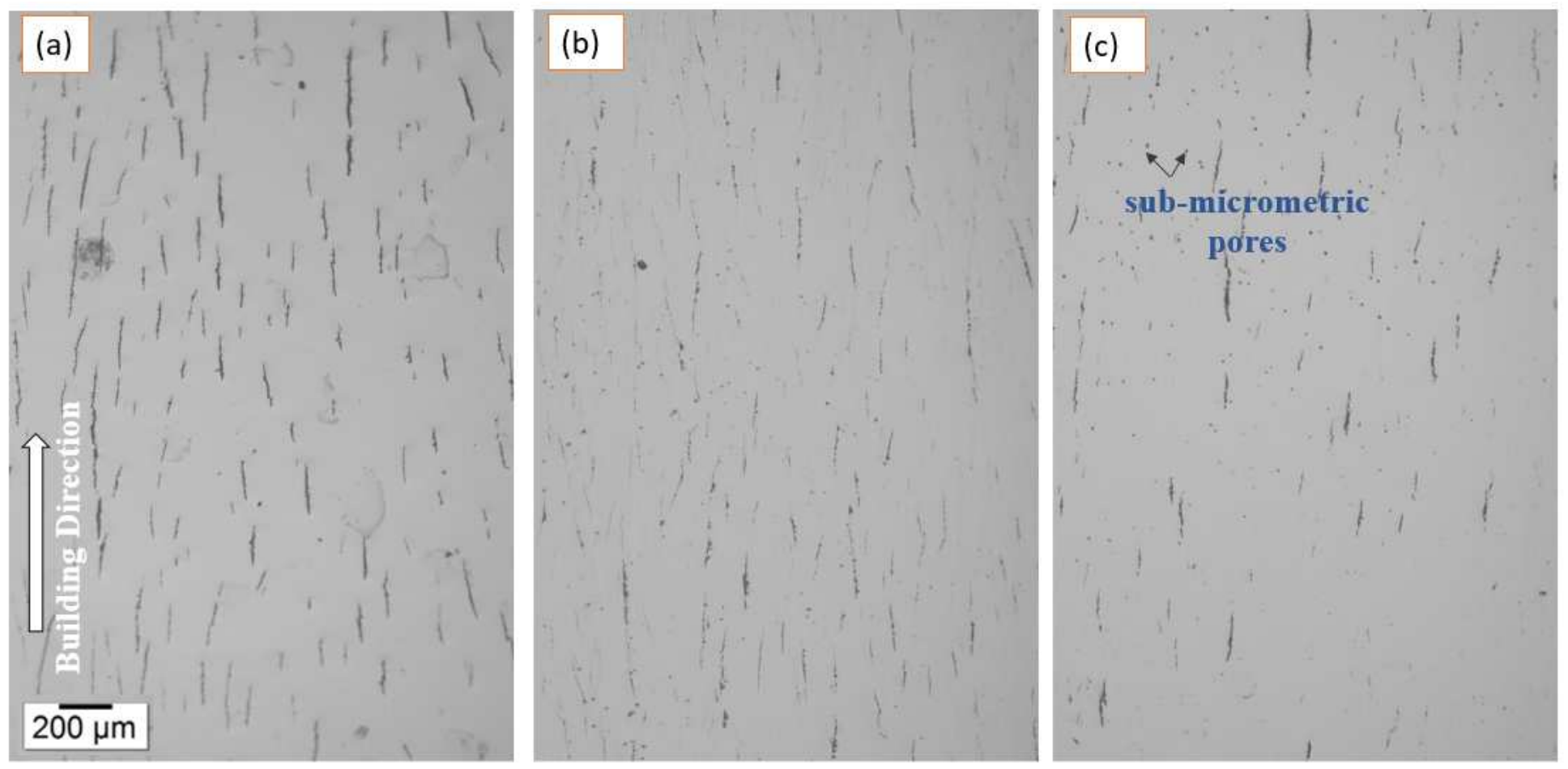

Figure 4

OM images of ground and polished IN713LC samples built using different energy densities: (a) $360 \mathrm{~J} / \mathrm{m}$; (b) $280 \mathrm{~J} / \mathrm{m}$; (c) $210 \mathrm{~J} / \mathrm{m}$.

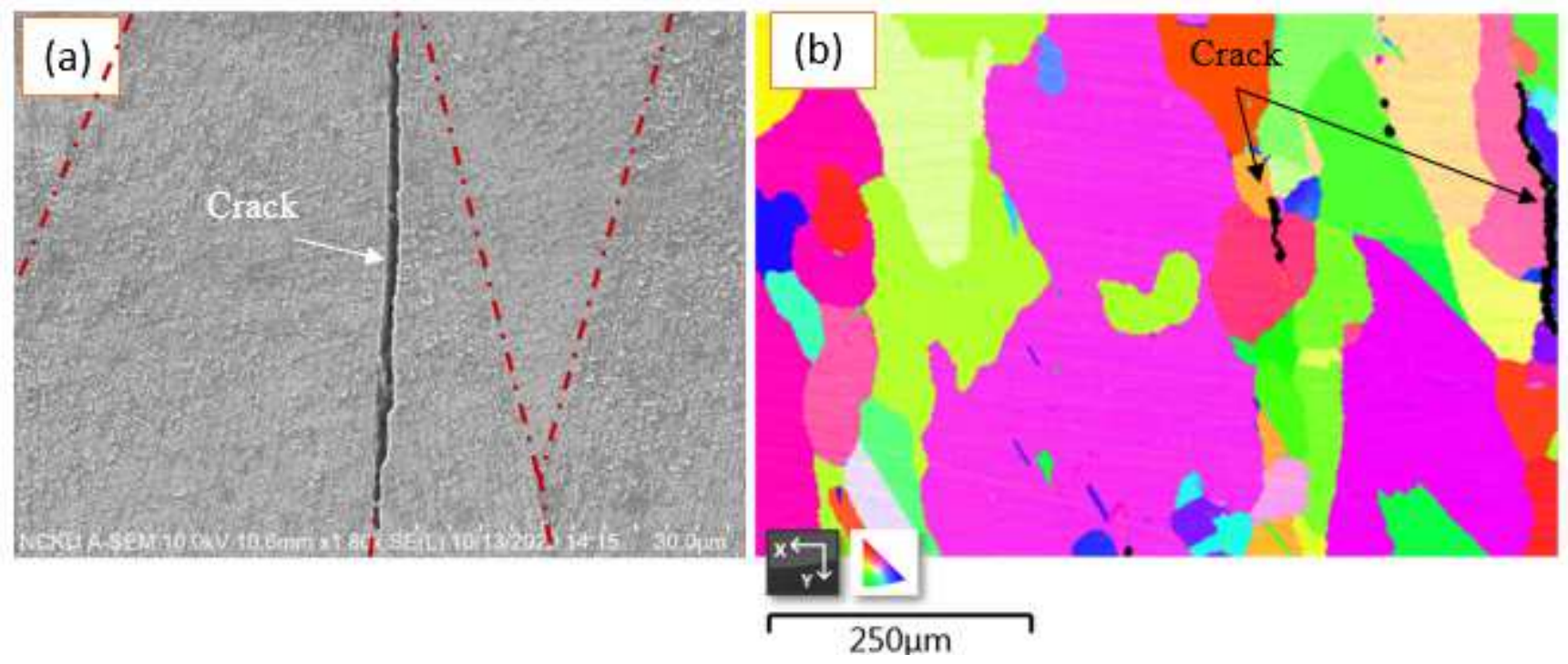

Figure 5

Crack details: (a) backscattered SEM micrograph; (b) EBSD map of grain-boundary crack in as-fabricated IN713LC sample. 


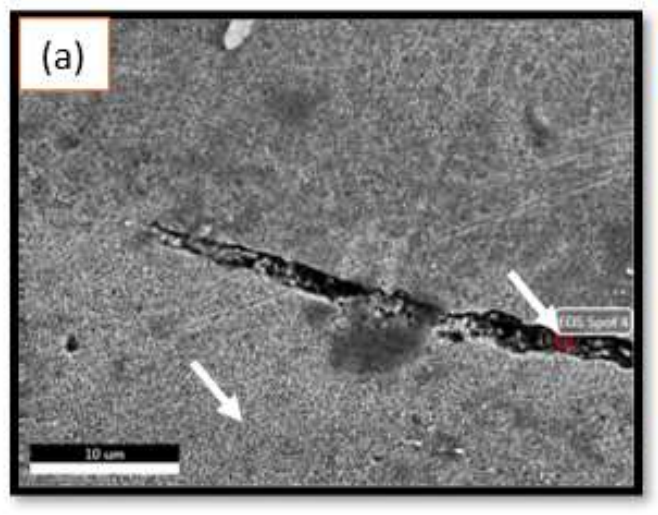

\begin{tabular}{|c|c|c|c|c|c|c|}
\hline (b) & $\mathrm{Cr}$ & $\mathrm{Mo}$ & $\mathrm{Nb}$ & $\mathrm{Al}$ & $\mathrm{Ti}$ & $\mathrm{C}$ \\
\hline $\begin{array}{c}\text { Initial } \\
\text { Powder }\end{array}$ & 12.1 & 4.1 & 2.0 & 6.2 & 0.77 & 0.05 \\
\hline $\begin{array}{c}\text { Inside of } \\
\text { crack }\end{array}$ & 4.43 & 2.65 & 11.54 & 16.08 & 24.42 & 21.54 \\
\hline $\begin{array}{c}\text { Outside of } \\
\text { crack }\end{array}$ & 22.24 & 4.08 & 0.78 & 4.23 & 0.64 & 2.82 \\
\hline
\end{tabular}

Figure 6

Element concentration in IN713LC sample fabricated using energy density of $360 \mathrm{~J} / \mathrm{m}$. (a) Points selected for EDS analysis, (b) alloying element concentrations inside and outside of crack.

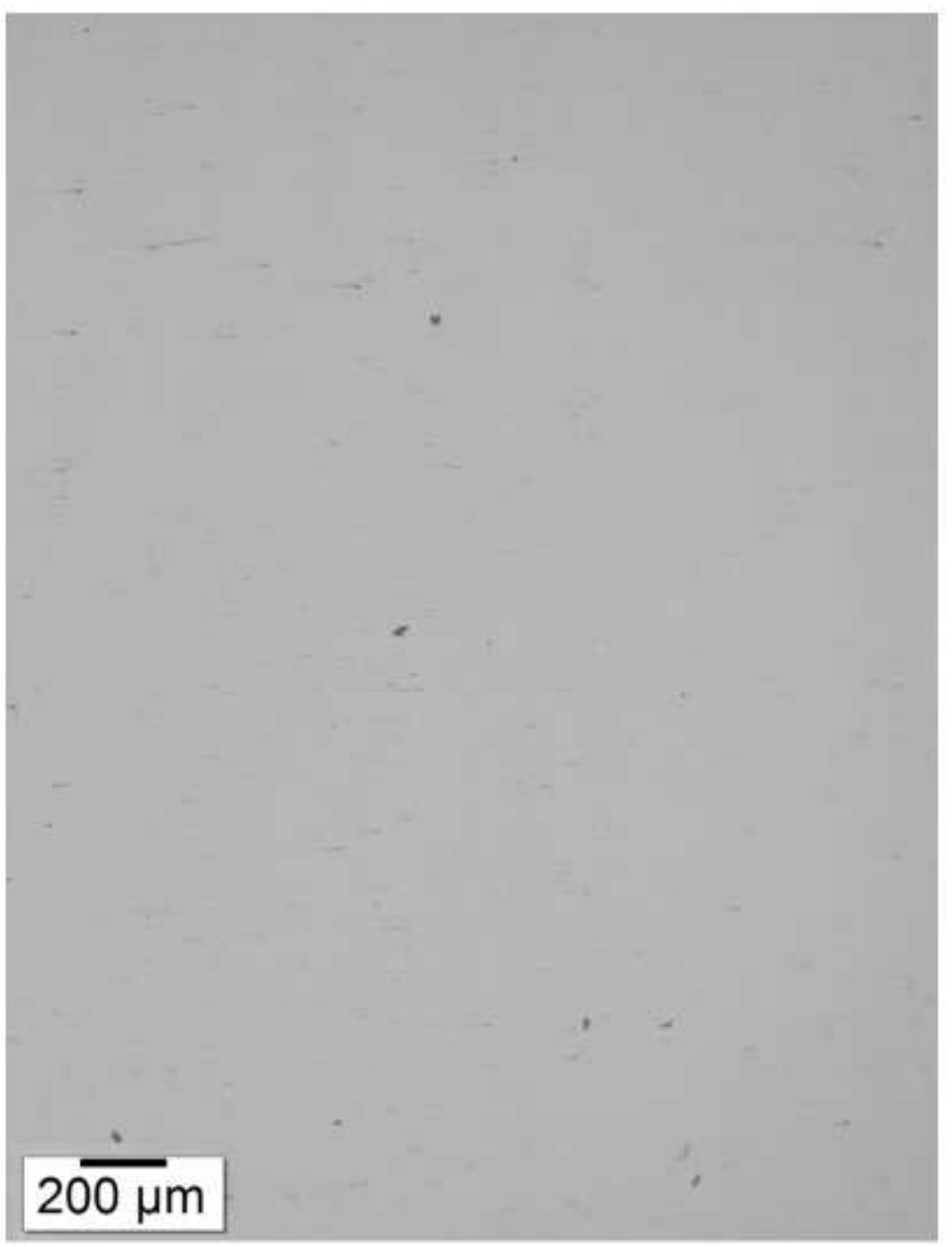

Figure 7

IN713LC sample fabricated using low energy density of $170 \mathrm{~J} / \mathrm{m}$. 